\title{
Cultivo de alface em diferentes manejos de cobertura do solo e fontes de adubação
}

\author{
Ana R. D. Ziech¹, Paulo C. Conceição ${ }^{2}$, Augusto V. Luchese ${ }^{3}$, Dalva Paulus ${ }^{4} \&$ Magnos F. Ziech $^{5}$
}

${ }^{1}$ UTFPR. Dois Vizinhos, PR. E-mail: reginautfpr@yahoo.com.br (Autor correspondente)

${ }^{2}$ UTFPR. Dois Vizinhos, PR. E-mail: paulocesar@utfpr.edu.br

${ }^{3}$ UFPR. Palotina, PR. E-mail: aluchese@gmail.com

${ }^{4}$ UTFPR. Dois Vizinhos, PR. E-mail: dalvapaulus@utfpr.edu.br

${ }^{5}$ UTFPR. Dois Vizinhos, PR. E-mail: magnos@utfpr.edu.br

Palavras-chave:

Lactuca sativa

manejo do solo

cama de aviário

produtividade

\begin{abstract}
R E S U M O
Com o objetivo de avaliar o desenvolvimento da alface e a atividade dos microrganismos em diferentes manejos de cobertura do solo e fontes de adubação foi desenvolvido, na Universidade Tecnológica Federal do Paraná - Câmpus Dois Vizinhos, no período compreendido entre maio de 2010 a janeiro de 2011, um experimento com delineamento de blocos ao acaso, em arranjo fatorial com parcelas subdivididas $(5 \times 3)$ e três repetições. A cultura de cobertura do solo foi aveia, manejada em plantio direto; palha incorporada; palha inteira via adição externa sobre o canteiro; palha picada via adição externa sobre o canteiro e um sistema sem uso de palhada. Para a adubação foram utilizados composto orgânico e adubo químico, além de uma testemunha sem adubação. Determinaram-se o número de folhas por planta, o diâmetro do caule e da parte aérea, massa da matéria fresca, produtividade de matéria fresca e seca, além da atividade dos microrganismos do solo. No primeiro ciclo a cultura da alface não foi influenciada pelos diferentes manejos de cobertura do solo nem pelas fontes de adubação. $\mathrm{O}$ adubo orgânico promoveu maior número de folhas no segundo cultivo. A manutenção da cobertura do solo e o composto orgânico promovem maior atividade microbiana ao longo do tempo.
\end{abstract}

\section{Key words:}

Lactuca sativa soil management poultry manure productivity

\section{Cultivation of lettuce under different management of land cover and nutrient sources}

\begin{abstract}
A B S T R A C T
With the objective to assess the development of lettuce and activity of the microorganisms under different managements of land cover and sources of fertilization, an experiment in a randomized block design in a factorial arrangement with split plots $(5 \times 3)$ and three replications was conducted at the Universidade Tecnológica Federal do Paraná, Câmpus Dois Vizinhos, during the period from May 2010 to January 2011. The cover crop was oat, under no tillage system; conventional tillage; whole straw via external addition on the bed; chopped straw via external addition on the bed and a system without the use of straw. For fertilization organic compost and chemical fertilizer were used and a control plot without fertilization. The number of leaves per plant, stem diameter and aerial part, mass of fresh matter, yield of fresh and dry matter, as well as the activity of soil microorganisms were determined. In the first cycle the lettuce crop was not influenced by different managements land cover and nutrient sources. The organic fertilizer promoted greater number of leaves, in the second cultivation. The maintenance of the soil cover and organic compound promotes greater microbial activity over time.
\end{abstract}

\section{INTRODUÇÃo}

A alface (Lactuca sativa L.) tem grande importância na alimentação humana destacando-se como fonte de vitaminas e sais minerais, além de se constituir a hortaliça folhosa mais popular consumida no país. Este valor se deve não só ao sabor e à qualidade nutritiva mas também pela facilidade de aquisição e baixo custo ao consumidor (Oliveira et al., 2004).

No estado do Paraná a produção de alface na safra 2010/2011 foi de 83.638 toneladas ocupando uma área de 4.308 hectares (SEAB/DERAL, 2012). De modo geral, a produção de hortaliças é uma alternativa para os pequenos produtores haja vista não haver demanda por grandes áreas; ademais, o cultivo de alface apresenta grande retorno econômico por área cultivada sendo, portanto, uma atividade agrícola adequada às características da região Sudoeste do Paraná, que se caracteriza por possuir propriedades de pequeno porte com mão de obra familiar.

A intensa movimentação do solo aplicada à produção de hortaliças é um fator de degradação e favorece a ocorrência de erosão (Souza \& Resende, 2006) contribuindo para perdas na quantidade e na qualidade da matéria orgânica e consequente redução da produtividade (Cividanes et al., 2002). Para garantir a sustentabilidade dos produtores familiares no campo a manutenção da qualidade do solo, é fundamental. 
Algumas técnicas têm sido utilizadas no cultivo da alface para minimizar os problemas relacionados ao manejo excessivo do solo destacando-se a utilização de cobertura morta "mulching" e a aplicação de adubos orgânicos. O "mulching" se constitui de uma prática pela qual se aplica, ao solo, material orgânico ou inorgânico, para que se forme uma camada em superfície com a finalidade de proteger a cultura e o próprio solo contra a ação de intempéries (Souza \& Resende, 2006).

Carvalho et al. (2005) concluíram, ao estudar o efeito de diferentes materiais (palha de arroz, palha de café, capim brachiaria, serragem e testemunha sem cobertura) na produtividade de alface que, independente da cobertura utilizada em superfície, os melhores resultados foram obtidos com o uso de material orgânico sobre os canteiros.

A utilização de adubação orgânica oriunda de estercos de animais e compostos orgânicos, de diferentes origens, tem sido utilizada no cultivo de hortaliças em muitas propriedades agrícolas.

Embora a aplicação de fertilizantes minerais em alface seja uma prática agrícola que traz resultados satisfatórios em termos de produtividade, o uso desordenado pode comprometer a qualidade final do produto e até mesmo prejudicar a saúde dos consumidores, além de onerar os custos de produção (Souza et al., 2005).

Os microrganismos do solo e o resultado de sua atividade têm sido apontados como um dos atributos mais sensíveis às alterações na qualidade do solo, causadas por mudanças de uso e práticas de manejo (Lopes et al., 2012). Isto evidencia o efeito das modificações, de forma antecipada, em relação aos demais atributos (Balota et al., 2004).

A quantificação da respiração microbiana é uma forma de estimar o nível de atividade dos microrganismos do solo e reflete na taxa de decomposição da matéria orgânica ou de algum outro material a ele adicionado (Severino et al., 2004) com consequente liberação de nutrientes às plantas. Sá et al. (2000) relatam que diferentes formas de manejo do solo e de fertilizante nitrogenado podem alterar os componentes biológicos.

Objetivou-se então, neste trabalho, estudar diferentes manejos de cobertura do solo e fontes de adubação nos parâmetros agronômicos da cultura da alface e na atividade respiratória dos microrganismos do solo.

\section{Material e Métodos}

O experimento foi desenvolvido na Unidade de Ensino e Pesquisa em Olericultura da Universidade Tecnológica Federal do Paraná - UTFPR, Câmpus Dois Vizinhos, situada a $25^{\circ} 42^{\prime} 52^{\prime \prime}$ de latitude S e longitude de 5303' $94^{\prime \prime}$ W-GR, a $530 \mathrm{~m}$ acima do nível do mar. O solo local é classificado como Nitossolo Vermelho Distroférrico (Bhering et al., 2008). O clima da região é Cfa (subtropical) sem estação seca definida cuja temperatura média do mês mais quente é de $22{ }^{\circ} \mathrm{C}$, conforme classificação de Köppen.

O delineamento experimental foi de blocos ao acaso, arranjo fatorial $5 \times 3$, em parcelas subdivididas, os quais foram constituídos por manejos da cobertura do solo e fontes de adubação, com três repetições. Nas parcelas principais $(1,2 \mathrm{x}$ 3,6 m) foram estabelecidos os manejos de cobertura do solo, compostos por 75 plantas, dentre as quais foram avaliadas 27 , pertencentes à área útil. Nas subparcelas $(1,2 \times 1,2 \mathrm{~m})$ foram distribuídas as seguintes fontes de adubação: orgânica, química e testemunha (sem o fornecimento de adubação) tendo-se avaliado nove plantas na porção central da parcela. Utilizou-se, para bordadura, uma linha adicional de plantas em volta das áreas avaliadas.

Os manejos de cobertura do solo com uso de aveia preta (Avena strigosa L.) foram: plantio direto sobre palha (PD); palha incorporada ao solo (IC); palha inteira via adição externa sobre o canteiro (PEI); palha picada $(10 \mathrm{~cm})$ via adição externa sobre o canteiro (PEP) e sistema convencional usado tradicionalmente sem palhada (SC).

Previamente ao início do experimento, o solo havia sido preparado de forma mecanizada com enxada rotativa em área total. A semeadura de aveia preta $(03 / 05 / 2010)$ nas parcelas que receberam adubação verde e cobertura do solo foi realizada de forma manual, em linhas, com espaçamento de $0,15 \mathrm{~m}$ entre si e densidade de sementes de $100 \mathrm{~kg} \mathrm{ha}^{-1}$.

Procedeu-se à eliminação periódica das plantas daninhas nas parcelas que permaneceram sem cobertura durante o período hibernal (PEI, PEP e SC). A determinação da massa da matéria seca (MS) da aveia foi realizada junto ao manejo, na fase de pleno florescimento $(26 / 08 / 2010)$ com coleta de biomassa em área de $0,25 \mathrm{~m}^{2}$, secada em estufa de circulação de ar forçado $\left(65^{\circ} \mathrm{C}\right)$ e pesado.

A quantidade de massa seca adicionada aos tratamentos que receberam palha externa de aveia, $\mathrm{PEI}$ e PEP, foi equivalente à produção média da espécie, obtida sob cultivo em PD e IC, correspondente a 13,9 $\mathrm{Mg} \mathrm{ha}^{-1}$ de MS (6 kg por parcela). Para o manejo com incorporação dos resíduos de aveia ao solo utilizou-se um minitrator equipado com enxada rotativa.

Como fonte de adubação orgânica utilizou-se composto de esterco de aves (cama de aviário) previamente fermentado. A adubação química se constituiu da aplicação de nitrogênio mineral cuja fonte foi a ureia ( $45 \%$ de N) parcelada em duas aplicações, aos 15 e 30 dias após o transplante das mudas.

As doses de ambas as fontes de adubação foram calculadas conforme a análise química do solo $\left(\mathrm{pH}\right.$ em $\mathrm{CaCl}_{2}=6,0 ; \mathrm{P}=$ $109,77 \mathrm{mg} \mathrm{dm}^{-3} ; \mathrm{K}=1,27 \mathrm{cmol} \mathrm{dm}_{\mathrm{c}}^{-3} ; \mathrm{Ca}=10,75 \mathrm{cmol}_{\mathrm{c}} \mathrm{dm}^{-3} ; \mathrm{Mg}$ $=4,38 \mathrm{cmol}_{c} \mathrm{dm}^{-3} ; \mathrm{H}+\mathrm{Al}=2,76 \mathrm{cmol}_{c} \mathrm{dm}^{-3} ; \mathrm{SB}=16,4 \mathrm{cmol}_{c} \mathrm{dm}$ ${ }^{3} ; \mathrm{V}=85,57 \%$ e $\mathrm{MO}=51,94 \mathrm{~g} \mathrm{dm}^{-3}$ ) seguindo as recomendações da CQFS RS/SC (2004) conforme a necessidade de nitrogênio (N) para a cultura de alface $\left(80 \mathrm{~kg} \mathrm{ha}^{-1}\right)$.

Para a adubação orgânica utilizou-se, além da análise de solo, a análise do composto orgânico (cama de aviário) que apresentava os seguintes valores de nutrientes: $\mathrm{Ca}=28$ $\mathrm{g} \mathrm{kg}^{-1} ; \mathrm{Mg}=6,8 \mathrm{~g} \mathrm{~kg}^{-1} ; \mathrm{P}_{2} \mathrm{O}_{5}=49,9 \mathrm{~g} \mathrm{~kg}^{-1} ; \mathrm{K}_{2} \mathrm{O}=48,4 \mathrm{~g} \mathrm{~kg}^{-1}$; $\mathrm{N}=1,5 \mathrm{~g} \mathrm{~kg}^{-1}$. Utilizou-se a aplicação da cama de aviário em equivalência à quantidade de $\mathrm{N}$ aplicado na adubação química resultando em $55 \mathrm{Mg} \mathrm{ha}^{-1}$ do composto, com aplicação a lanço sobre as subparcelas, uma semana antes do transplante das mudas de alface. 
Visando ao melhor aproveitamento das coberturas dos canteiros, foram realizados dois cultivos sucessivos de alface do tipo crespa, com características de folhas soltas e coloração verde-claro; no primeiro ciclo (15/09 a 26/10/2010) utilizou-se a cv. Grand Rapids; as mudas foram produzidas em bandejas de poliestireno com 280 células utilizando-se substrato comercial $\left(\right.$ GerminaPlant $\left.{ }^{\circledR}\right)$ irrigadas duas vezes ao dia e mantidas em ambiente protegido.

O transplante das mudas ocorreu quando as mesmas apresentavam de três a quatro folhas, 34 dias após a semeadura (DAS) com espaçamento de 0,25 x 0,25 m. Após o transplante utilizou-se irrigação por aspersão, duas vezes ao dia; não foram necessárias aplicações de tratos culturais no controle de pragas e doenças. A colheita foi realizada 41 dias após o transplante através do arranquio das plantas para evitar que o sistema radicular da alface cultivada no primeiro ciclo interferisse no cultivo seguinte.

Apesar da cv. Grand Rapids ser indicada para cultivo o ano todo observou-se, durante o mês de outubro, tendência das plantas com indução ao florescimento precoce, característica extremamente indesejável em alface; desta forma utilizou-se, no segundo ciclo (27/11/2010 a 09/01/2011) a cv. Veneranda, adaptada aos cultivos de verão com resistência ao pendoamento precoce; enfim, as mudas e o manejo da irrigação foram realizados da mesma forma descrita no primeiro ciclo de cultivo, as quais foram transplantadas 37 DAS e colhidas 43 dias após o transplante.

As variáveis de planta analisadas foram: número total de folhas por planta (NF); diâmetro médio do caule (DC) obtido com uso de paquímetro digital logo abaixo das primeiras folhas; diâmetro da parte aérea (cabeça) medido pela distância entre os quadrantes da planta (DPA); massa da matéria fresca por planta (sem raiz) (MF); produtividade de matéria fresca da parte aérea (MFPA). A parte aérea das plantas foi submetida a pré-secagem e posteriormente levada à estufa com circulação de ar na temperatura de $65{ }^{\circ} \mathrm{C}$ para obtenção da massa da matéria seca (MSPA).

Avaliou-se a atividade respiratória dos microrganismos do solo (ARM) nos diferentes tratamentos, após a colheita das alfaces, aos 62 e 154 dias após o manejo das culturas de inverno, para os ciclos 1 e 2 , respectivamente.

As amostras de solo foram coletadas na camada de 0 a $5 \mathrm{~cm}$, passadas em peneira de $2 \mathrm{~mm}$ e colocadas (100 g) em recipientes de vidro (câmaras de incubação) com capacidade de $1 \mathrm{~L}$ contendo, no seu interior, um copo com $25 \mathrm{~mL}$ de $\mathrm{NaOH}\left(0,5 \mathrm{~mol} \mathrm{~L}^{-1}\right)$ para capturar o $\mathrm{CO}_{2}$ liberado pelos microrganismos.

As câmaras de incubação foram vedadas e incubadas sob temperatura controlada de $\pm 25^{\circ} \mathrm{C}$ em BOD, durante 28 dias. Para titulação foram adicionados, às amostras, $1 \mathrm{~mL}$ de $\mathrm{BaCl}_{2}$ (50\% saturado), três gotas de indicador fenolftaleína (1\%) e tituladas com solução de $\mathrm{HCl}\left(0,5 \mathrm{~mol} \mathrm{~L}^{-1}\right)$ conforme descrito por Alef (1995).

A liberação de $\mathrm{CO}_{2}$ produzido foi estimada através da fórmula: $\mathrm{CO}_{2}=\left(\mathrm{V}_{1}-\mathrm{V}_{0}\right) \times 44$, proposta por Severino et al. (2004) em que: $\mathrm{CO}_{2}$. Quantidade de carbono mineralizado ( $\mathrm{mg}$ de $\mathrm{CO}_{2} \mathrm{~g}_{\mathrm{g}}$ solo ${ }^{-1}$ ); $\mathrm{V}_{1}$ - Volume de $\mathrm{HCl}$ necessário para neutralizar o $\mathrm{NaOH}$ no tratamento $(\mathrm{mL}) ; \mathrm{V}_{0}$ - Volume de $\mathrm{HCl}$ necessário para neutralizar a testemunha $(\mathrm{mL})$ e $44=$ peso molar do $\mathrm{CO}_{2}$.

Os dados foram submetidos à análise de variância (ANOVA) e as médias comparadas pelo teste de Tukey ( $\mathrm{p} \leq$ 0,05 ), pelo programa computacional Assistat 7.6 Beta (Silva \& Azevedo, 2006).

\section{Resultados e Discussão}

Para os sistemas de manejo da cobertura do solo e fontes de adubação, verificaram-se efeitos isolados nas características analisadas, exceto para a respiração dos microrganismos do solo no primeiro ciclo de cultivo, que apresentou interação significativa $(\mathrm{p} \leq 0,01)$ pela análise de variância (Tabela 1$)$.

Os diferentes manejos das coberturas do solo não influenciaram no diâmetro de caule da cultura, em ambos os ciclos de cultivo (Tabela 2). Andrade Júnior et al. (2005) avaliaram duas cultivares de alface tipo lisa (Regina e Elisa) sobre diferentes coberturas e também não constataram efeitos significativos para o diâmetro médio de caule.

Tabela 1. Valores de F com respectivas significâncias obtidos na análise de variância (ANOVA) para as variáveis: DC - diâmetro médio do caule (mm); DPA - diâmetro da parte aérea $(\mathrm{cm})$; NF - número total de folhas; MFPA - matéria fresca da parte aérea $\left(\mathrm{kg} \mathrm{ha}^{-1}\right)$; MF - matéria fresca da planta $\left(\mathrm{g}\right.$ planta $\left.{ }^{-1}\right)$; MSPA - massa da matéria seca da parte aérea $\left(\mathrm{kg} \mathrm{ha}^{-1}\right)$; ARM - atividade respiratória dos microrganismos $\left({\mathrm{mg} \mathrm{de} \mathrm{CO}_{2} \mathrm{~g} \text { de solo }}^{-1}\right)$ em dois ciclos de cultivo de alface sobre diferentes manejos de cobertura e fontes de adubação

\begin{tabular}{|c|c|c|c|c|c|c|c|}
\hline Fatores & $\overline{D C}$ & DPA & NF & MFPA & MF & MSPA & ARM \\
\hline & & & & Ciclo 1 & & & \\
\hline Blocos & $8,17^{\star}$ & $0,47^{\text {ns }}$ & $2,71^{\mathrm{ns}}$ & $1,37^{\mathrm{ns}}$ & $1,37^{\mathrm{ns}}$ & $0,75^{\mathrm{ns}}$ & $0,28^{\text {ns }}$ \\
\hline Trat a (manejos) & $0,50^{\text {ns }}$ & $0,50^{\text {ns }}$ & $1,04^{\mathrm{ns}}$ & $1,36^{\text {ns }}$ & $1,35^{\mathrm{ns}}$ & $0,53^{\text {ns }}$ & $0,64^{\mathrm{ns}}$ \\
\hline Trat b (adubação) & $2,00^{\text {ns }}$ & $3,34^{\mathrm{ns}}$ & $1,36^{\mathrm{ns}}$ & $2,16^{\mathrm{ns}}$ & $2,16^{\text {ns }}$ & $2,02^{\text {ns }}$ & 55,96 ** \\
\hline \multirow[t]{2}{*}{ Interação (a x b) } & $0,55^{\mathrm{ns}}$ & $1,48^{\text {ns }}$ & $2,19^{\text {ns }}$ & $0,59^{\text {ns }}$ & $0,59^{\text {ns }}$ & $1,07^{\text {ns }}$ & $7,33^{\star *}$ \\
\hline & & & & Ciclo 2 & & & \\
\hline Blocos & $0,19^{\text {ns }}$ & $7,11^{*}$ & $1,99^{\text {ns }}$ & $1,75^{\mathrm{ns}}$ & $1,14^{\mathrm{ns}}$ & $5,94^{*}$ & $0,05^{\text {ns }}$ \\
\hline Trat a (manejos) & $3,39^{\text {ns }}$ & $7,82^{\star \star}$ & $7,84^{\star *}$ & $4,22^{\star}$ & $3,20^{\text {ns }}$ & $4,61^{*}$ & $10,68 * *$ \\
\hline Trat b (adubação) & $8,07^{* *}$ & $5,14^{*}$ & 12,00 ** & $6,57^{\star \star}$ & $1,60^{\text {ns }}$ & $6,92^{* *}$ & $345,25^{\text {** }}$ \\
\hline Interação $(\mathrm{a} \times \mathrm{b})$ & $0,54^{\mathrm{ns}}$ & $0,45^{\text {ns }}$ & $0,52^{\mathrm{ns}}$ & $0,31^{\text {ns }}$ & $0,79^{\text {ns }}$ & $1,31^{\mathrm{ns}}$ & $1,85^{\mathrm{ns}}$ \\
\hline
\end{tabular}

${ }^{*},{ }^{* *}$ e ns: Significativo pelo teste $F$ com probabilidade $p \leq 0,05 ; p \leq 0,01$ e não significativo, respectivamente 
Tabela 2. Valores médios* para diâmetro de caule, diâmetro da parte aérea e número de folhas de alface (Lactuca sativa L.) cultivadas sobre diferentes sistemas de manejo do solo e fontes de adubação

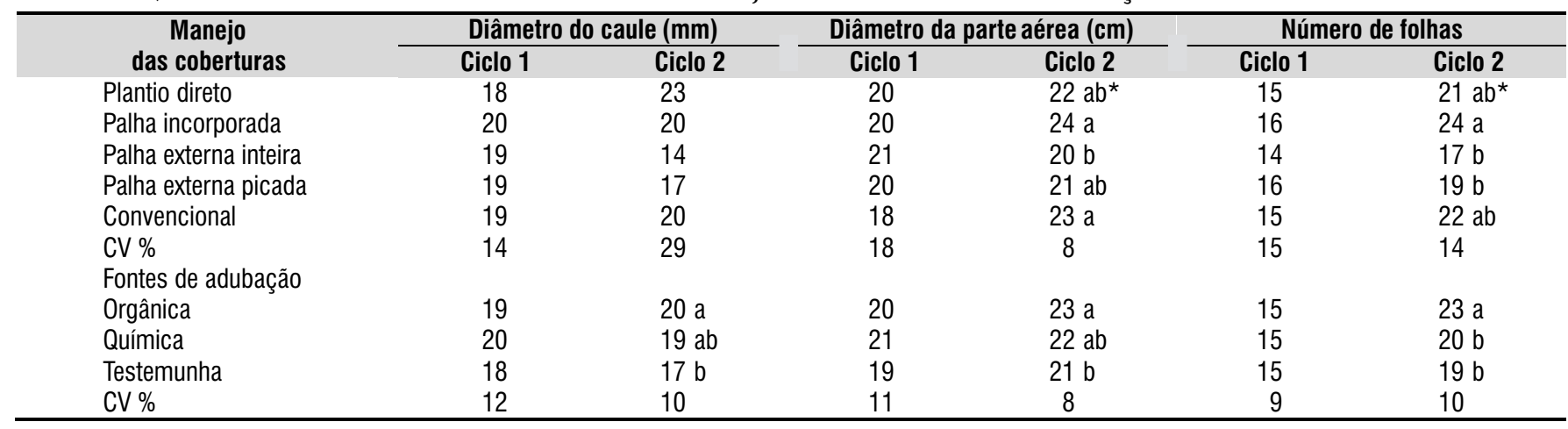

* Médias seguidas pela mesma letra na coluna não diferem estatisticamente entre si, pelo teste de Tukey $(p<0,05)$

As fontes de adubação não apresentaram diferenças significativas quanto às características agronômicas das plantas durante o primeiro ciclo (Tabela 2); portanto, se assemelham à testemunha. A ausência de resposta da alface à aplicação dos adubos está relacionada, provavelmente, à elevada fertilidade natural do solo da área experimental suprindo, assim, as necessidades da cultura neste primeiro cultivo; já no segundo ciclo de cultivo o DPA da alface foi influenciado pelos sistemas de manejo das coberturas, onde o IC e o SC apresentaram as maiores médias, com $24 \mathrm{e} 23 \mathrm{~cm}$, respectivamente, não diferindo do PD nem do PEP (Tabela 2). Resultados superiores foram obtidos por Fontanétti et al. (2006) em cultivo de alface cv. Raider sobre adubação verde, com diâmetro médio de $38,5 \mathrm{~cm}$.

A adubação orgânica proporcionou, no ciclo sucessivo, maiores diâmetros de caule e da parte aérea, diferindo apenas da testemunha (Tabela 2).

O número de folhas por planta (ciclo 2) respondeu, de forma diferenciada, aos sistemas de manejo cuja IC resultou em maior média (24 folhas) diferindo estatisticamente dos manejos com adição de palha externa em superfície do solo (Tabela 2) seja ela picada ou inteira.

Os manejos PD e SC apresentaram produção de folhas em números intermediários (Tabela 2); desta maneira, observa-se que o não revolvimento do solo possui potencial para ser usado em substituição ao SC, sobretudo no que diz respeito ao aspecto visual de qualidade do produto em que o cultivo de hortaliças sobre canteiros que contém cobertura do solo proporciona folhas mais limpas diminuindo as perdas no processo de lavagem e seleção.

Efeitos positivos da utilização de materiais orgânicos para cobertura dos canteiros também são relatados por Andrade Júnior et al. (2005) com médias de 22 e 27 folhas por planta, respectivamente, para alface do tipo lisa cvs. Elisa e Regina, produzidas sobre diferentes tipos de cobertura. Por sua vez, Carvalho et al. (2005) obtiveram, para a cv. Regina 2000 cultivada sobre coberturas de capim, palha de arroz, palha de café e serragem, médias entre 35 e 40 folhas por planta.

A adição de adubo orgânico promoveu aumento no número de folhas de alface no segundo ciclo de cultivo (Tabela 2) diferenciando-se estatisticamente da adubação química e da testemunha; é provável que este efeito tenha ocorrido em virtude do fornecimento de outros nutrientes advindos da cama de aviário, além do $\mathrm{N}$ que possivelmente se tornaram disponíveis em função da mineralização promovida pelos microrganismos do solo, ao longo do primeiro ciclo.

O maior rendimento de folhas de alface com uso de adubos orgânicos, foi atribuído por Oliveira et al. (2010) aos efeitos proporcionados por esses resíduos sobre as propriedades químicas, físicas e biológicas do solo uma vez que eles atuam como condicionadores e aumentam a capacidade do solo em armazenar nutrientes necessários para o desenvolvimento das plantas.

Os sistemas de manejo e fontes de adubação não influenciaram na produtividade, durante o primeiro ciclo de cultivo, com produções médias de $141 \mathrm{~g}$ planta $^{-1}$ e $22.727 \mathrm{~kg}$ ha $^{-1}$, para MF e MFPA, respectivamente (Tabela 3).

No cultivo sucessivo (ciclo 2 ) a média de produção de MF foi de $239 \mathrm{~g}$ planta $^{-1}$, com ausência de diferenças estatísticas entre os sistemas de manejo das coberturas e fontes de adubação (Tabela 3). Resultados do presente estudo são superiores aos encontrados por Mógor \& Câmara (2007) para a cv. Verônica cultivada sobre diferentes manejos de cobertura com palha de aveia preta (188 g planta $\left.^{-1}\right)$.

O manejo com IC dos resíduos promoveu, no segundo ciclo, maior produtividade de MFPA (45.966 $\left.\mathrm{kg} \mathrm{ha}^{-1}\right)$ diferindo somente do manejo com adição PEI $\left(24.835 \mathrm{~kg} \mathrm{ha}^{-1}\right)$ para a cobertura (Tabela 3). Ferreira et al. (2009) também não verificaram diferenças na produção de massa fresca total de alface cultivada em plantio direto e solo descoberto, cuja resposta em relação à produtividade média foi de $12.150 \mathrm{~kg} \mathrm{ha}^{-1}$.

Os rendimentos médios da MFPA verificados no presente estudo (Tabela 3) são superiores à média de produtividade de $19.415 \mathrm{~kg} \mathrm{ha}^{-1}$ do estado do Paraná, para a safra 2010/2011 (SEAB/DERAL, 2012).

A adição de adubos orgânicos ao solo contribui de acordo com o grau de decomposição e consequente mineralização desses resíduos, interferindo diretamente na disponibilidade de nutrientes para as plantas, em especial para aquelas de ciclo curto, como o da alface (Peixoto Filho et al., 2013) podendo apresentar efeitos imediatos ou residuais, influenciando nos cultivos subsequentes.

O adubo orgânico promoveu, no segundo ciclo, maior produtividade de MFPA de alface diferindo apenas da 
Tabela 3. Produtividade média da matéria fresca da parte aérea (MFPA); massa da matéria seca da parte aérea (MSPA) e peso da matéria fresca por planta (MF) de alface (Lactuca sativa L.) cultivada sobre diferentes sistemas de manejo de coberturas do solo e fontes de adubação

\begin{tabular}{|c|c|c|c|c|c|c|}
\hline \multirow{2}{*}{$\begin{array}{c}\text { Manejo } \\
\text { das coberturas }\end{array}$} & \multicolumn{3}{|c|}{ Ciclo 1} & \multicolumn{3}{|c|}{ Ciclo 2} \\
\hline & $\begin{array}{c}\text { MFPA } \\
\left(\mathrm{kg} \mathrm{ha}^{-1}\right)\end{array}$ & $\begin{array}{c}\text { MF } \\
\text { (g planta-1) }\end{array}$ & $\begin{array}{c}\text { MSPA } \\
\left(\mathrm{kg} \mathrm{ha}^{-1}\right)\end{array}$ & $\begin{array}{c}\text { MFPA } \\
\left(\mathrm{kg} \mathrm{ha}^{-1}\right)\end{array}$ & $\begin{array}{c}\text { MF } \\
\text { (g planta-1) }\end{array}$ & $\begin{array}{c}\text { MSPA } \\
\left(\mathrm{kg} \mathrm{ha}^{-1}\right)\end{array}$ \\
\hline Plantio direto & 20.382 & 127 & 1.296 & $37.847 a b^{*}$ & 263 & $1.875 \mathrm{ab}$ \\
\hline Palha incorporada & 23.654 & 147 & 1.361 & $45.966 \mathrm{a}$ & 322 & $2.196 \mathrm{a}$ \\
\hline Palha externa inteira & 22.272 & 139 & 1.180 & $24.835 b$ & 189 & $1.580 \mathrm{~b}$ \\
\hline Palha externa picada & 28.532 & 177 & 1.459 & $31.560 a b$ & 183 & $1.767 \mathrm{ab}$ \\
\hline Convencional & 18.797 & 117 & 1.268 & $37.311 \mathrm{ab}$ & 240 & $2.017 \mathrm{ab}$ \\
\hline CV\% & 42 & 42 & 33 & 32 & 40 & 17 \\
\hline \multicolumn{7}{|l|}{ Fontes de adubação } \\
\hline Orgânica & 24.492 & 152 & 1.395 & $42.154 \mathrm{a}$ & 282 & $2.132 \mathrm{a}$ \\
\hline Química & 24.044 & 149 & 1.362 & $34.515 a b$ & 225 & $1.816 \mathrm{~b}$ \\
\hline Testemunha & 19.646 & 122 & 1.181 & $29.842 \mathrm{~b}$ & 211 & $1.714 \mathrm{~b}$ \\
\hline Média & 22.727 & 141 & 1.313 & 35.504 & 239 & 1.887 \\
\hline CV\% & 31 & 31 & 24 & 26 & 48 & 17 \\
\hline
\end{tabular}

* Médias seguidas pela mesma letra na coluna não diferem estatisticamente entre si, pelo teste de Tukey $(p \leq 0,05)$

testemunha (Tabela 3). Referidos resultados corroboram com Peixoto Filho et al. (2013) que observaram melhor produtividade de alface cv. Crespa Cacheada com o uso de esterco de frango $\left(26.720 \mathrm{~kg} \mathrm{ha}^{-1}\right)$ seguido do fertilizante mineral $\left(21.636 \mathrm{~kg} \mathrm{ha}^{-1}\right)$; no entanto, com produtividades inferiores às do presente estudo. Conforme Oliveira et al. (2010) as hortaliças folhosas respondem muito bem à adubação orgânica exercendo influência no desempenho agronômico das culturas.

A atividade respiratória dos microrganismos do solo apresentou, no primeiro ciclo, interação entre os sistemas de manejo da cobertura do solo e fontes de adubação (Tabela 4) em que o PD, IC e o PEP promoveram a menor atividade microbiana entre os manejos utilizados.

O comportamento dos microrganismos do solo com a utilização de adubo químico, foi similar ao da testemunha, para os manejos de cobertura utilizando o PEI e o SC (Tabela 4) apresentando as menores emissões de $\mathrm{CO}_{2}$, o que indica menor atividade da microbiota do solo. Souza (2005) indica que a utilização de adubos químicos promove redução na atividade biológica do solo podendo afetar o desempenho produtivo das culturas.

No cultivo sucessivo da hortaliça (ciclo 2) sobre os mesmos manejos das coberturas, o PD apresentou a maior atividade respiratória diferindo estatisticamente do sistema IC e SC (Figura 1A). De acordo com Ferreira et al. (2007) a mobilização

Tabela 4. Interação entre médias da respiração dos microrganismos de solo, ao final do primeiro ciclo de cultivo de alface sobre diferentes sistemas de manejo do solo e fontes de adubação

\begin{tabular}{|c|c|c|c|}
\hline \multirow{3}{*}{$\begin{array}{c}\text { Manejo } \\
\text { das coberturas }\end{array}$} & \multicolumn{3}{|c|}{ Fontes de adubação } \\
\hline & Orgânica & Química & Testemunha \\
\hline & \multicolumn{3}{|c|}{ (mg de $\mathrm{CO}_{2} \mathrm{~g}$ de solo ${ }^{-1}$ ) } \\
\hline Plantio direto & $3,82 \mathrm{bA}^{*}$ & $2,85 \mathrm{aA}$ & $2,66 \mathrm{aA}$ \\
\hline Palha incorporada & $3,88 \mathrm{bA}$ & $2,40 \mathrm{aA}$ & $2,75 \mathrm{aA}$ \\
\hline Palha externa inteira & 6,83 aA & $1,96 \mathrm{aB}$ & $2,57 \mathrm{aB}$ \\
\hline Palha externa picada & $3,89 \mathrm{bA}$ & $2,95 \mathrm{aA}$ & $2,51 \mathrm{aA}$ \\
\hline Convencional & $6,96 \mathrm{aA}$ & $1,25 \mathrm{aB}$ & $1,28 \mathrm{aB}$ \\
\hline
\end{tabular}

*Médias seguidas pela mesma letra minúscula na coluna e maiúscula na linha, não diferem estatisticamente entre si pelo teste Tukey $(p \leq 0,05)$

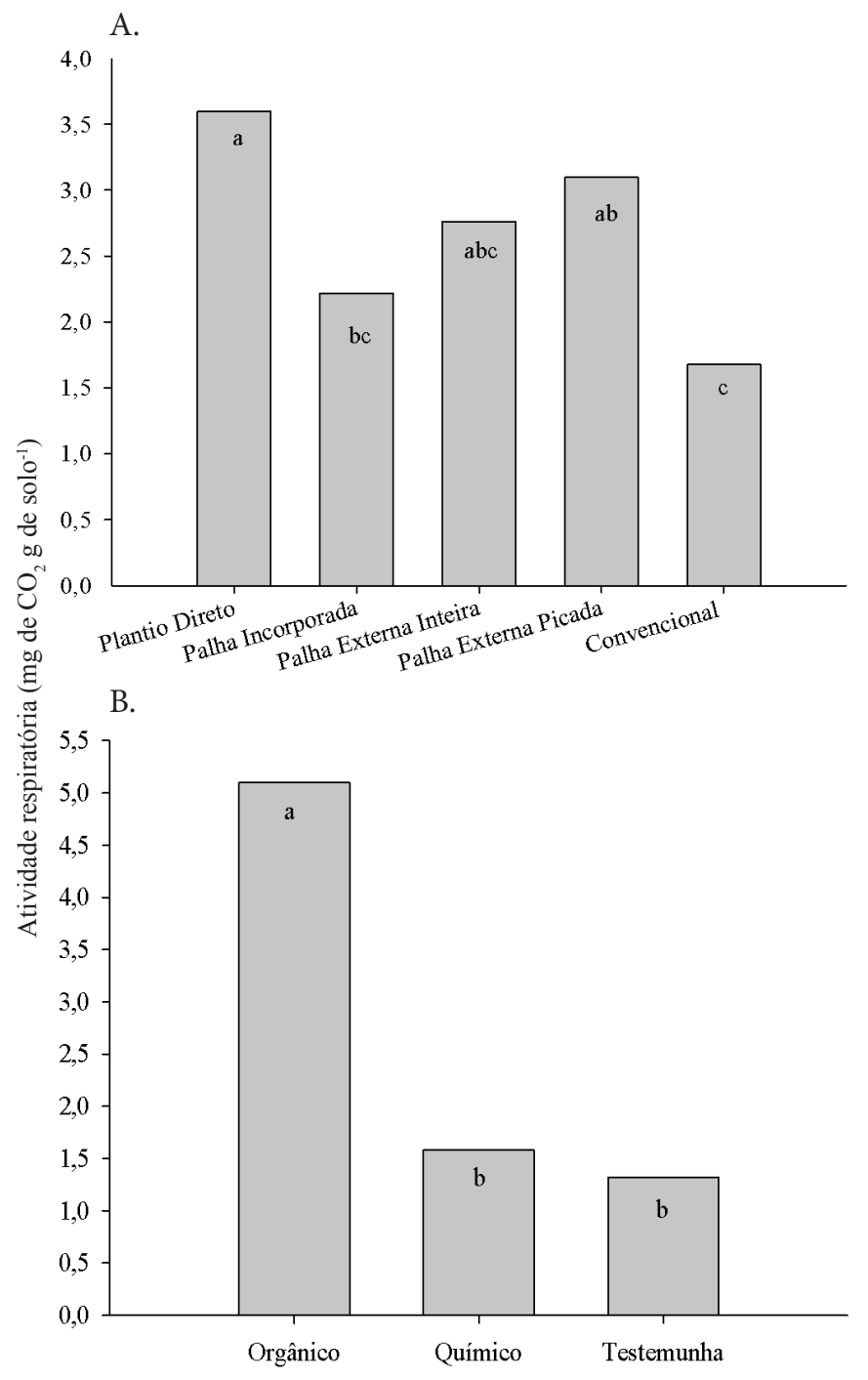

Letras minúsculas iguais sobre barras indicam ausência de efeito estatístico pelo teste de Tukey $(p>0,05)$ entre os fatores analisados

Figura 1. Atividade respiratória dos microrganismos do solo, ao final do segundo ciclo de cultivo de alface (Lactuca sativa L.) sobre os sistemas de manejo das coberturas (A) e fontes de adubação (B) 
do solo e consequente incorporação de resíduos orgânicos da superfície, podem elevar a biomassa microbiana em curto prazo, por disponibilizar substrato orgânico.

A permanência de resíduos de palha de aveia em cobertura, seja ela cultivada no local (PD) ou depositada superficialmente (PEP e PEI) promoveu a manutenção da microbiota já existente no solo por maior período de tempo (Figura 1A). Alvarez et al. (1995) também verificaram, na camada de 0 a $5 \mathrm{~cm}$, maior taxa respiratória em condições de plantio direto em relação ao solo arado; este efeito pode estar associado à ocorrência de condições adversas externas nos sistemas revolvidos.

A maior ARM ocorreu com a aplicação de adubação orgânica (Figura 1B.) diferindo do adubo químico e da testemunha. A elevada taxa respiratória dos microrganismos indica maior atividade microbiana para decomposição do material orgânico do solo, com consequente liberação de nutrientes às plantas (Sá et al., 2000).

Oliveira et al. (2009) constataram que os compostos orgânicos incrementam a biomassa microbiana devido ao aumento nas proporções de carbono e nitrogênio lábeis estimulando diretamente a microbiota do solo. Desta forma, a manutenção da cobertura do solo e adição de resíduos orgânicos favorecem a atividade dos microrganismos.

\section{Conclusões}

1. No primeiro cultivo a cultura da alface não apresentou diferenças significativas para as variáveis de crescimento (diâmetro do caule, da parte aérea e número de folhas) nos diferentes manejos de cobertura do solo e fontes de adubação; no cultivo sucessivo o plantio direto foi similar em produtividade de massa fresca da parte aérea em relação aos manejos convencionais.

2. No segundo cultivo a adubação orgânica resultou em maior número de folhas.

3. Os manejos de cobertura do solo, plantio direto e cobertura com palha externa sob adubação orgânica, promovem maior atividade microbiana, ao longo do tempo.

\section{Literatura Citada}

Alef, K. Estimation of soil respiration. In: Alef, K.; Nannipieri, P. Métodos in applied soil microbiology and biochemistry. London: Academic Press, 1995. 576p.

Alvarez, R.; Díaz, R. A.; Barbero, N.; Santanatoglia, O. J.; Blotta, L. Soil organic carbon, microbial biomass and $\mathrm{CO}_{2}-\mathrm{C}$ production from three tillage systems. Soil and Tillage Research, v.33, p.17-28, 1995.

Andrade Júnior, V. C.; Yuri, J. E.; Nunes, U. R.; Pimenta, F. L.; Matos, C. S. M.; Florio, F. C. A.; Madeira, D. M. Emprego de tipos de cobertura de canteiro no cultivo da alface. Horticultura Brasileira, v.23, p.899-903, 2005.

Balota, E. L.; Colozzi Filho, A.; Andrade, D. S.; Dicr, R. P. Longterm tillage and crop rotation effects on microbial biomass and $\mathrm{C}$ and $\mathrm{N}$ mineralization. Soil and Tillage Research, v.77, p.137-145, 2004.
Bhering, S. B.; Santos, H. G dos. Mapa de solos do estado do Paraná: legenda atualizada. 1.ed. Rio de Janeiro: Embrapa Floresta/Embrapa Solos, 2008. 74p.

Carvalho, J. E.; Zanella, F.; Mota, J. H.; Lima, A. L. S. Cobertura morta do solo no cultivo de alface cv. Regina 2000, em Ji-Paraná, RO. Ciência e Agrotecnologia, v.29, p.935-939, 2005.

Cividanes, F. J. Efeitos do sistema de plantio e da consorciação soja-milho sobre artrópodes capturados no solo. Pesquisa Agropecuária Brasileira, v.37, p.15-23, 2002.

CQFS RS/SC - Comissão de Química e Fertilidade do Solo. Manual de adubação e calagem para os estados do Rio Grande do Sul e Santa Catarina. 10.ed. Porto Alegre: Sociedade Brasileira de Ciência do Solo, 2004. 400p.

Ferreira, E. A. B.; Resck, D. V. S.; Gomes, A. C.; Ramos, M. L. G. Dinâmica do carbono da biomassa microbiana em cinco épocas do ano em diferentes sistemas de manejo do solo no cerrado. Revista Brasileira de Ciência do Solo, v.31, p.1625-1635, 2007.

Ferreira, R. L. F.; Araújo Neto, S. E.; Silva, S. S.; Abud, E. A.; Rezende, M. I. F. L.; Kusdra, J. F. Combinações entre cultivares, ambientes, preparo e cobertura do solo em características agronômicas de alface. Horticultura Brasileira, v.27, p.383-388, 2009.

Fontanétti, A.; Carvalho, G. J.; Gomes, L. A. A.; Almeida, K.; Moraes, S. R. G.; Teixeira, C. M. Adubação verde na produção orgânica de alface americana e repolho. Horticultura Brasileira, v.24, p.146-150, 2006.

Lopes, H. S. S.; Medeiros, M. G.; Silva, J. R.; Júnior Medeiros, A.; Santos, M. N.; Batista, R. O. Biomassa microbiana e matéria orgânica em solo de Caatinga, cultivado com melão na Chapada do Apodi, Ceará. Revista Ceres, v.59, p.565-570, 2012.

Mógor, A. F.; Câmara, F. L. A. Produção de alface em sistema orgânico em sucessão a aveia preta, sobre palha, e diferentes coberturas do solo. Scientia Agrária, v.8, p.239-245, 2007.

Oliveira, A. C. B.; Sediyama, M. A. N.; Pedrosa, M. W.; Garcia, N. C. P.; Garcia, S. L. R. Divergência genética e descarte de variáveis em alface cultivada sob sistema hidropônico. Acta Scientiarum Agronomy, v.26, p.211-217, 2004.

Oliveira, E. Q.; Souza, R. J.; Cruz, M. C. M.; Marques, V. B.; França, A. C. Produtividade de alface e rúcula, em sistema consorciado, sob adubação orgânica e mineral. Horticultura Brasileira, v.28, p.36-40, 2010.

Oliveira, L. C.; Stangarlin, J. R.; Lana, M. do C., Simon, D.; Zimmermann, A. Biomassa microbiana em cultivo de alface sob diferentes adubações orgânicas e manejo da adubação verde. Revista Brasileira de Agroecologia, v.4, p.182-185, 2009.

Peixoto Filho, J. U.; Freire, M. B. G. dos; Freire, F. J.; Miranda, M. F. A.; Pessoa, L. G. M.; Kamimura, K. M. Produtividade de alface com doses de esterco de frango, bovino e ovino em cultivos sucessivos. Revista Brasileira de Engenharia Agrícola e Ambiental, v.17, p.419-424, 2013. 
Sá, T. C. L. L.; Marques, M.; Vasconcellos, C. A.; Pereira Filho, I.; França, G. E.; Cruz, J. C. Envolvimento de dióxido de carbono e mineralização de nitrogênio em latossolo vermelho-escuro com diferentes manejos. Pesquisa Agropecuária Brasileira, v.35, p.581-589, 2000.

SEAB/DERAL - Secretaria da Agricultura e do Abastecimento - Departamento de Economia Rural do Estado do Paraná. Olericultura - Análise da conjuntura agropecuária (2012). <http://www.agricultura.pr.gov.br/arquivos/File/deral/ Prognosticos/olericultura_2012_13.pdf >. 5 Fev. 2013.

Severino, L. S.; Costa, F. X.; Beltrão, N. E. de M.; Lucena, A. M. A. de. Mineralização da torta de mamona, esterco bovino e bagaço de cana estimada pela respiração microbiana. Revista de Biologia e Ciências da Terra, v.5, p.1-7, 2004.
Silva, F. de A. S.; Azevedo, C. A. V. de. A new version of the assistat-statical assistance software. In: World Congress on Computers in Agriculture, 4, 2006, Orlando. Anais...Orland: American Society of Agricultural and Biological Engineers, 2006. p.393-396.

Souza, J. A. Generalidades sobre efeitos benéficos da matéria orgânica na agricultura. Informe Agropecuário, v.26, p.7-8, 2005.

Souza, J. L.; Resende, P. L. Manual de Horticultura orgânica. 2.ed. Viçosa: Aprenda Fácil, 2006. 843p.

Souza, P. A.; Negreiros, M. Z.; Menezes, J. B.; Bezerra Neto, F.; Souza, G. L. F. M.; Carneiro, C. R.; Queiroga, R. C. F. Características químicas de alface cultivada sob efeito residual da adubação com composto orgânico. Horticultura Brasileira, v.23, p.754-757, 2005. 